\title{
Investigation of Radiation Shielding Properties of Polypropylene Fiber Reinforced Shotcrete
}

\author{
M.A. ÇAKIROĞLU* \\ Suleyman Demirel University, Technical Education Faculty, 32260 Isparta, Turkey
}

\begin{abstract}
Fibre concrete has emerged in order to improve the properties of concrete and to create an economical building material. In this study, the radiation permeability of shotcrete reinforced with polypropylene fiber was investigated. For this purpose, linear attenuation coefficient was measured for shotcrete reinforced with polypropylene fiber, produced using the dry mixing process. The linear attenuation coefficients for dry mixed shotcrete have been measured at photon energies of 1173, 1332 and $662 \mathrm{keV}$. Measurements were carried out using gamma spectrometer containing $\mathrm{NaI}(\mathrm{Tl})$ detector and a Multichannel Analyzer (MCA). The linear attenuation coefficients have increased with the increasing fiber percentage for all studied gamma energies.
\end{abstract}

DOI: 10.12693/APhysPolA.129.705

PACS/topics: $81.05 . \mathrm{Ni}, 78.20 . \mathrm{Ci}$

\section{Introduction}

The use of various mixtures of concrete has brought along some new developments. For specific objectives there are many different kinds of concrete with different characteristics in terms of both application and design. One such concrete is the shotcrete. Shotcrete can be applied using both the dry and wet methods. Shotcrete, which has a very wide variety of application, may be exposed to harmful elements, such as radiation.

Generally, concrete is mixed with metallic fibers, fibers of natural origin, glass fibers, synthetic fibers based on polymers, such as nylon and polypropylene, polyethylene. Shotcrete is a special concrete and it may incorporate various types of steel or synthetic fibers. One of the fibers added to shotcrete is polypropylene fiber. Polypropylene fibers can be used in industrial plants, airports, housing and swimming pools, since polyproplene fiber increases the impermeability, impact and abrasion strength of the material $[1,2]$. Shotcrete is successfully applied to repair and strengthen buildings as well as in the newly built structures. Shotcrete, has wide applications, it can withstand exposure to the harmful weather, ultraviolet radiation, ozone and so on.

All living creatures on Earth are continuously exposed to radiation from natural radionuclides, through the respiratory and digestive system, indoor work areas as well as through the exposure to artificial sources of radiation. The dangers which might arise from radiation exposure are known to everyone. However, despite all of the bad effects of radiation, there are also great benefits especially, in the analysis of some biological problems and in the treatment of cancer. Inasmuch as we can not remove the risk of radiation from our lives, we need to take protective measures to minimize the radiation hazards [3]. Radiation absorbing materials have been an

*e-mail: meldaalkan@sdu.edu.tr important issue [4]. There is a large number of studies investigating the linear attenuation coefficient of radiation and strength of concrete produced with different building materials and the shielding properties and the mechanical properties of heavy concrete produced with different aggregates or with barite. However there is quite a limited number of studies done on shotcrete. In this study the radiation shielding properties of shotcrete dry mixed with polypropylene fibers were evaluated by determining the linear attenuation coefficient.

\section{Materials and methods}

The increase in the fiber content of both polyproplene fibers and steel fibers in fiber-reinforced concretes improves mechanical properties of the concrete [5]. In this study the polypropylene fiber-reinforced concrete and concrete without fiber ( $\mathrm{Y} 0$ ) were produced by adding different amounts of polypropylene fibers $\left(1 \mathrm{~kg} / \mathrm{m}^{3}\right.$ (PP1), $3 \mathrm{~kg} / \mathrm{m}^{3}$ (PP3) and $5 \mathrm{~kg} / \mathrm{m}^{3}$ (PP5)) to dry mix shotcrete. In the dry mix method the dry aggregate and cement are mixed and this mixture comes to nozzle through pipe and hose under a high air pressure and is sprayed on to the surface by adding water to the mixture at the end of the hose. Maximum grain size used in shotcrete application was $8 \mathrm{~mm}$. Aggregate is between $70 \% 0-5 \mathrm{~mm}$ and $30 \% 5-8 \mathrm{~mm}$. CEM I 42.5 cement $500 \mathrm{~kg} / \mathrm{m}^{3}$ was used in the experiments. Water/cement ratio was regulated through the valve at the hose end by the operator. Sigunit Dust AL admixture, in the amount of $5.5 \%$ of cement quantity, and the drinking water were used in the production of concrete.

In this study four panels $\left(450 \times 450 \mathrm{~mm}^{2}\right)$ have been prepared in accordance with the TSE 11747 standard [6]. One panel was prepared without admixture of fibers and rest of the shotcrete panels were prepared by adding different amounts of polypropylene fibers, as was discussed above. One core sample with a diameter of $100 \mathrm{~mm}$ and a width of $100 \mathrm{~mm}$ was cut from each panel. Samples with widths of 20,30 and $50 \mathrm{~mm}$ were cut from the core sample using a natural stone cutting tool. 
The linear attenuation coefficients of concretes have been measured using the gamma spectrometer system containing $\mathrm{NaI}(\mathrm{Tl})$ detector coupled with full featured $16 \mathrm{k}$ multichannel digital spectrum analyzer (DSPEC LF) with advanced digital signal processing techniques, and were recorded using the MAESTRO-32 gamma spectroscopy software. The measurements have been performed at gamma energies of 662, 1173 and $1332 \mathrm{keV}$, obtained from ${ }^{60} \mathrm{Co}$ radioactive source. The schematic arrangement of the experimental setup used in the present study is shown in Fig. 1.

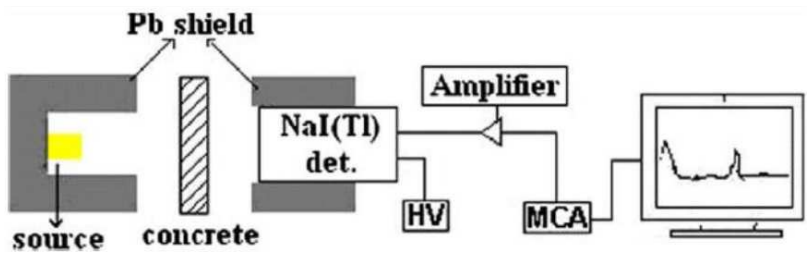

Fig. 1. Schematic view of the experimental setup [7].

The attenuation coefficients have been evaluated by comparison of $N$ and $N_{0}$, which are the count rates measured by the detector, with and without the absorber of thickness $x$, respectively, using equation

$$
N=N_{0} \mathrm{e}^{-\mu x},
$$

where: $N$ intensity of radiation transmitted through material of thickness $x, N_{0}$ is the incoming radiation intensity and $\mu$ is linear attenuation coefficient [7].

\section{Results}

The obtained results are displayed in Table I. The linear attenuation coefficients of different types of shotcrete, for different gamma photon energies, are shown in Fig. 2. It is clearly seen from Fig. 2 that the linear attenuation coefficient increases with increasing fiber percentage for all studied gamma energies.

\section{TABLE I}

Measured linear attenuation coefficients $\left(\mathrm{cm}^{-1}\right)$.

\begin{tabular}{c|c|c|c}
\hline \hline Sample & $662 \mathrm{keV}$ & $1173 \mathrm{keV}$ & $1332 \mathrm{keV}$ \\
\hline Y0 & 0.1851269 & 0.1158507 & 0.0992019 \\
PP1 & 0.1916005 & 0.1304414 & 0.1062793 \\
PP3 & 0.1954338 & 0.1323811 & 0.1065247 \\
PP5 & 0.1985809 & 0.1343026 & 0.1070424
\end{tabular}

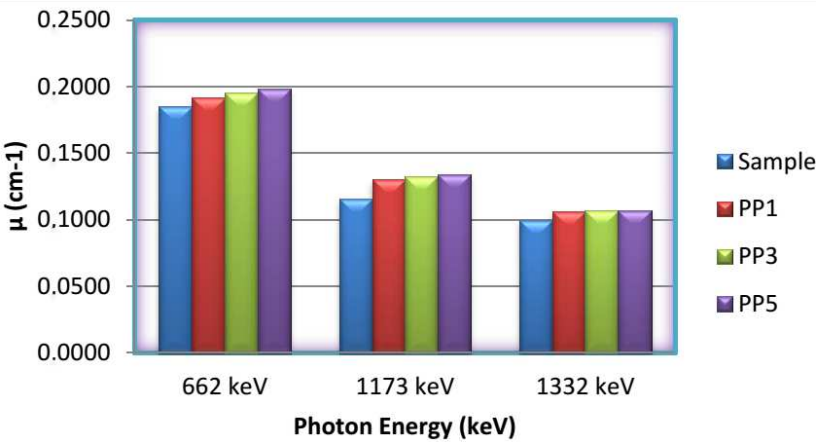

Fig. 2. Measured linear attenuation coefficients.

\section{Conclusions}

In the study the linear attenuation coefficients for dry mix shotcrete have been measured at photon energies of 1173, 1332 and $662 \mathrm{keV}$. The linear attenuation coefficients depend on incident photon energy, the atomic number and the density of the shielding materials [8]. Study shows that the linear attenuation coefficients slightly increases with the increasing content of fiber in the concrete at all tested photon energies. The linear attenuation coefficient decreases with the increasing energy of gamma photon.

\section{References}

[1] S.T. Yıldırım, C.E. Ekinci, Sci. Eng. J. Furat Univ. 18, 359 (2006).

[2] H. Bolat, Ph.D. Thesis, Gazi University Institute of Science and Technology, 2009.

[3] İ. Akkurt, C. Başyiğit, A. Akkaş, B. Mavi, K. Günoğlu, e-J. NWSA Eng. Sci. 6, 1A0225 (2011).

[4] M. Filiz, O. Gençel, C. Özel, E. Sancak, Int. Ready Mixed Concr. Congr. 2008, Istanbul, p. 635.

[5] V. Afroughsabet, T. Ozbakkaloglu, Constr. Build. Mater. 94, 73 (2015).

[6] Turkish Standardization Institute, TS 11747, Rules for Mixing, Application and Curing of Shotcrete, Turkish Standardization Institute, 1st ed. ICS 91.100.30 (in Turkish), 1995.

[7] İ. Akkurt, K. Günoğlu, C. Başyiğit, A. Akkaş, Acta Phys. Pol. A 123, 374 (2013).

[8] J. Woods, Computational Methods in Reactor Shielding, Pergamon Press, New York 1982. 